\title{
A COMPARISON BETWEEN TRANSURETHRAL CYSTOLITHOCLASTY AND VESICOLITHOTOMY IN PEDIATRIC MALE PATIENTS
}

\author{
Muhammad Khalid ${ }^{a}$, Muhammad Faizan ${ }^{b}$, Muhammad Asif Gurmani ${ }^{c}$, Amjad Ali Siddiqui ${ }^{\mathrm{d}}$, Qadeer \\ Ahmed Choudhary ${ }^{e}$, Zulfiqar Anjum ${ }^{f}$ \\ associate Professor, HOD Urology, D.G Khan Medical College, Dera Ghazi Khan. \\ ${ }^{\mathrm{b}}$ Medical Officer, THQ Hospital Kot Chutta, Dera Ghazi Khan. \\ 'Assistant Professor, Department of Urology, D.G Khan Medical College, Dera Ghazi Khan. \\ ${ }^{d}$ District Consultant, Department of Urology, D.G Khan Medical College, Dera Ghazi Khan. \\ ${ }^{e}$ Associate Professor, Department of Urology Sahiwal Medical College, Sahiwal. \\ fAssociate Professor, Department of Pediatric Surgery, D.G Khan Medical College, Dera Ghazi \\ Khan.
}

\begin{abstract}
:
BACKGROUND \& OBJECTIVE: To compare transurethral cystolithoclasty with ureteroscope over open vesicolithotomy in pediatric male patients.

METHODOLOGY: Study comprises of hundred pediatric male patients, divided into two equal groups of 50 each, labeled as Group-A and Group-B. All the patients having stones less than $20 \mathrm{~mm}$ size (average $14 \mathrm{~mm}$ ) were included. Group-A patients were treated with transurethral cystolithoclasty by using ureteroscope and pneumatic lithoclast assisted with the help of Dormia basket. Group-B patients were treated with open vesicolithotomy.

RESULTS: All hundred male pediatric patients were between the ages of 1-15 years (mean age 8 years). Hospital stay was 2-3 days (average 2.5 days) in Group-A patients and 3-5 days (average 4 days) in Group-B patients. In Group-A3 (6\%) patients had urinary tract infection, $1(2 \%)$ had urethral injury and 2(4\%) had residual stone post-operatively. While Group-B4 (8\%) suffered from urinary tract infection, $1(2 \%)$ had wound infection, $1(2 \%)$ had hematuria, and $2(4 \%)$ had fever. Retention of urine was $1(2 \%)$ in each Group.
\end{abstract}

CONCLUSION: Transurethral cystolithoclasty is a much better way of treating vesical calculus in pediatric male patients because it is a procedure with short hospital stay, minimal invasion, no scar and less complication.

KEYWORDS: Bladder Calculus, Comparison, Cystolithoclasty, Ureteroscope, Pneumatic Lithoclast, Dormia basket, Vesicolithotomy.

doi: https://doi.org/10.37723/jumdc.v11i1.163

\section{How to cite this:}

Khalid M, Faizan M, Gurmani MA, Siddiqui AA, Choudhary QA, Anjum Z. A COMPARISON BETWEEN TRANSURETHRAL CYSTOLITHOCLASTY AND VESICOLITHOTOMY IN PEDIATRIC MALE PATIENTS. jumdc. $2020 ; 11(1): 31-38$.

doi: https://doi.org/10.37723/jumdc.v11i1.163

This is an Open Access article distributed under the terms of the Creative Commons Attribution License (http://creativecommons.org/licenses/by/4.0), which permits unrestricted use, distribution, and reproduction in any medium, provided the original work is properly cited. 


\section{INTRODUCTION:}

Bladder calculus is a disease that has been vanished mysteriously, a least from affluent industrialized countries but in past bladder calculi were more frequent in west and people tolerating this disease had risked their lives to get relief. Lithotomy or "Stone Cutting" via perineal route was that last source of help before 1800s- an extremely unpleasant procedure with high mortality ${ }^{[1]}$. However urinary bladder is the most common site for stone formation among the children and categorized as primary idiopathic / endemic secondary and migrant.

History of bladder calculus goes parallel with civilization and its roots go back to ancient Egyptians. Oldest bladder calculus was discovered in an Egyptians Mummy, dated about 4800 BC. Hippocrates (460-377 BC) defined the symptoms of bladder calculus, he told in his famous Oath of Medical Ethics "I will not cut for the stone, but will leave this to be done by practitioners of this work" At that time lithotomy via perineal root was the last treatment and wound of bladder was considered lethal ${ }^{[2,3]}$. Suprapubic Lithotomy was first performed by Pierre Franco in 1561 . The incidence of vesical calculi has declined significantly in developed nations due to nutritional and socioeconomic advancements ${ }^{[4]}$. The recurrence of stone in Pediatric patients is very high so every effort should be made to completely clear the stone. This is a greater challenge despite minimal invasive surgery and ESWL restrictions. To avoid stone reformation risk factors like anatomical and metabolic to be assessed by evaluating the diet, urine and stone analysis ${ }^{[5]}$.

Bladder calculus is a common problem in Pakistan. It is the most prevailing disorder in poor class people with high incidence in childhood and adolescence. Bladder calculi are managed by different modalities including open vesicolithotomy, extracorporeal or endocorporeal lithotripsy and endoscopic cystolitholapaxy or cystolithoclasty via a retrograde or ante grade approach, depending upon the availability of skills and gadgets. ESWL is the first line of treatment in majority of patients preferably in children ${ }^{[6,7]}$.In Pakistan conventional open vesicolithotomy procedure is
Corresponding Author:

Dr. Muhammad Khalid,

Associate Professor, HOD Urology,

D.G Khan Medical College, Dera Ghazi Khan.

Email:drkhalidb4@gmail.com

mostly used in managing large bladder calculi. Endoscopic procedures are being carried out in all the teaching hospitals of Punjab including Teaching hospital Dera Ghazi Khan and in certain District hospitals also. The aim of our work is to help the male children of bladder calculus with the maximum benefits of cystoscopic procedure that is why we have compared new adapting procedure with most common conventionally used procedure i.e. cystoscopic lithoclasty versus open vesicolithotomy.

\section{METHODOLOGY:}

A comparative study was conducted with prospective data collection in Department of Urology, Teaching hospital Dera Ghazi Khan, from October 2016 to October 2018 for a period of two years. The study has been approved by the Ethical review committee of Teaching Hospital Dera Ghazi Khan. Hundred pediatric male patients were included in this study.

Patients having vesical calculus in neurogenic bladder, bladder diverticulae, Calculus with post urethral valves, urethral strictures, vesico-cutaneous fistula, age below 1year and above 15 year in male patients and all the female patients were excluded from our study.

Male pediatric patients between the age 1 to 15 years having single calculus size less than $20 \mathrm{~mm}$ were included in this study.

Patients were selected and randomly divided into two Groups of fifty each. In Group-A patients, transurethral cystolithoclasty was done with help of ureteroscope and pneumatic lithoclast, large few pieces were removed with help of dormia basket and rest of the sand particles were left for spontaneous passage. At the end of procedure Foley catheter $8-12 \mathrm{Fr}$ was placed for 1-3 days in Group-A patients. In Group-B patients, open vesicolithotomy was done by giving Pfannenstiel's incision and Foley catheter of 8-12Fr was passed for 3-5 days 
post-operatively. All the male pediatric patients were operated under General Anesthesia and a single dose of prophylactic antibiotic was given to all patients pre-operatively. All the patients were evaluated by history, physical examination, complete blood count, renal function test, complete urine, ultrasound and $x$ ray $\mathrm{KUB}$, clotting factors and virology of hepatitis. Comparative data regarding age, hospital stay, expenses, catheter duration, stone free rate and complications were collected carefully.

In Group-A patients undergoing cystoscopic procedure hospital stay was 2-3 days ( 1 day pre-operatively and 1-2 days post-operatively) and in Group-B patients treated by open vesicolithotomy hospital stay was 3-5 days (2 days pre-operatively and 2-3 days postoperatively). Expenses of 1000 Rupees per day were noted in all pediatric male patients either undergoing cystoscopic procedure or conventional open vesicolithotomy. In GroupA, complications of urethral injury, retention of urine due to residual stone, and urinary tract infection were carefully handled. Patients with urethral injury and retention of urine were catheterized for five days. In patients having residual stone cystoscopic procedure was repeated, and patients with urinary tract infection were managed with appropriate injectable antibiotics. While in Group-B patients, wound infection, retention of urine, hematuria, fever and urinary tract infection were managed accordingly. Patients were discharged depending upon type of treatment procedure and their conditions. All the patients were followed up weekly for one month.

\section{RESULTS:}

From October 2016 to 2018, hundred pediatric male patients had been admitted in Department of Urology, Teaching hospital Dera Ghazi Khan, with diagnosis of bladder calculus. All of them were male patients; age ranges between 1-15 years (average age 8 years) with single urinary bladder stone less then $20 \mathrm{~mm}$ were included. Patients included in our study were mostly belonging to District Dera Ghazi Khan, Rajanpur and few from some Districts of Province Baluchistan.
In Group-A 50 patients and in Group-B 50 patients. Mean \pm S.D of Group-A and Group-B is respectively $2.5 \pm 0.5802,4 \pm 1.2616$. Anova results found to be Significant results between groups because $p$-value is $<0.05$ table-I.

In Group-A patients, hospital stay was from 2-3 days (average 2.5 days) and in Group-B from 35 days (average 4 days). Post-operatively urethral catheterization was done from 1-3 days (average 2 days) in Group-A, and from 3-5 days (average 4 days) in Group-B patients. Average expenses of 2500 Rs in Group-A and 4000 Rs in Group-B were noted. Expenses in Group-A were less as compared to Group-B due to short hospital stay. Stone free rate was $96 \%$ in Group-A and $100 \%$ in Group-B. All the results are shown in Figure-I (A-D) and the statistical application like one-way Anova was applied. It was observed a significant difference ( $P$-value $\leq$ 0.05 ) between both Groups-A and B on the basis of three parameters such as hospital stay, Post-operatively urethral catheterization and hospital expanses while in the case of stone free rate the difference was no significant or stone free survival in the group was a little better.

Patients undergoing cystoscopic procedure developed less complications (10\%) postoperatively as compared to the patients treated by open vesicolithotomy (18\%). In Group-A, one patient $(2 \%)$ had urethral injury which was managed by catheterization for five days. Though the cystoscopic instrument used for cystolithoclasty in pediatric male patients was ureteroscope and its initial portion has caliber of 7.5 Fr even then there were chances of urethral injury during procedure. Two patients (4\%) got retention of urine after removal of Foley catheter and on investigation found to have residual stone pieces. Two patients (4\%) developed urinary tract infection and were managed with injectable antibiotics and pain killer. In Group-B, one patient (2\%) developed wound infection, which was treated by injectable antibiotics. One patient $(2 \%)$ had hematuria and one patient (2\%) developed retention of urine and catheterization was kept for further few days. Four patients (8\%) developed urinary tract infection. Out of these four, two patients (4\%) developed fever along with urinary tract infection and were managed successfully with antipyretics and injectable 
antibiotics. When the post-operative complications of both Groups; Group-A (transurethral cystolithoclasty) and Group-B (open vesicolithotomy) were compare, it is evident from the Figure-II. There was a significant decrease ( $P$-value $\leq 0.05)$ in four complications in Group-A such as urinary tract infection, wound infection, fever, hematuria and uncontrolled bleeding. While, in the case of two complications such as urethral injury and urinary retention the Group-B patient were significantly better.

Table-I- Data Summary \& Anova Result

\begin{tabular}{|c|c|c|c|c|c|}
\hline Summary Groups & Count & Average & S.D & & \\
\hline $\begin{array}{l}\text { Transurethral } \\
\text { Cystolithoclasty }\end{array}$ & 50 & 2.5 & 0.580288 & & \\
\hline $\begin{array}{l}\text { Open } \\
\text { Vesicolithotomy }\end{array}$ & 50 & 4 & 1.26168 & & \\
\hline $\begin{array}{l}\text { ANOVA Source of } \\
\text { Variation }\end{array}$ & SS & $\mathrm{df}$ & MS & $\mathrm{F}$ & P-value \\
\hline Between Groups & 56.25 & 1 & 56.25 & \multirow[t]{2}{*}{58.33333} & \multirow[t]{2}{*}{0.000} \\
\hline Within Groups & 94.5 & 98 & 0.964286 & & \\
\hline Total & 150.75 & 99 & & & \\
\hline
\end{tabular}

(A)

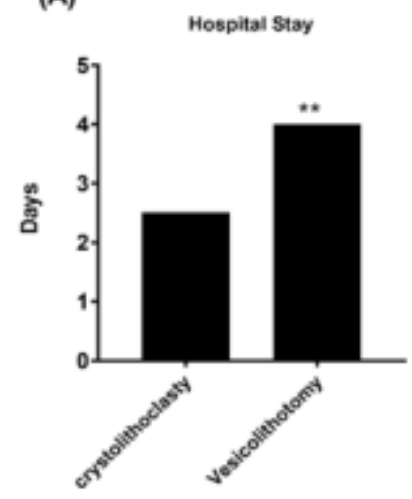

(C)

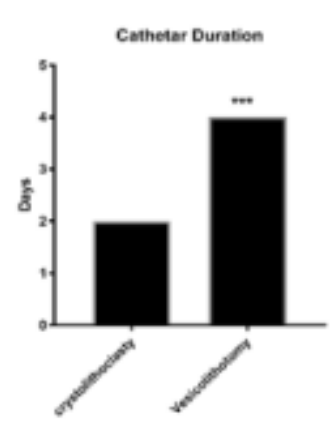

(B)

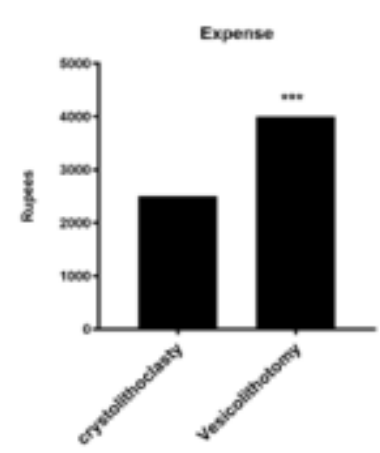

(D)

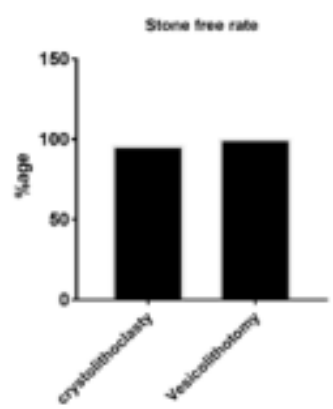

Figure-I: Comparison between the treatment Groups-A (transurethral cystolithoclasty) and B (open vesicolithotomy). (A) Duration of hospital stay, Group-A and B (B) Comparison of expanses (C) Catheter duration (D) Stone free period. Statistical analysis was done by implying one-way Anova and p-value was significant. Numbers of patients were fifty in each group. 
Post operative complications

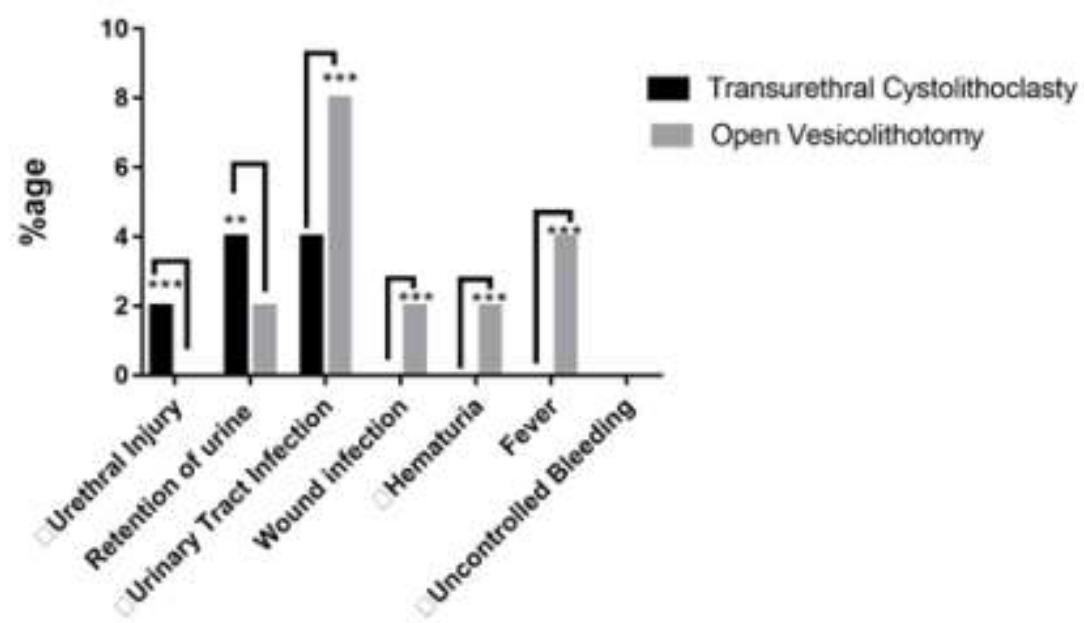

Figure-II: Comparison of post-operative complication between the treatment groups A (transurethral cystolithoclasty) and B (open vesicolithotomy). In Group-A post-operative complications; (black) Urinary tract infections, wound infection, Hematuria, Fever, Uncontrolled bleeding was significantly lower (P-value $\leq 0.05$ ). While in Group-B, post-operative complications; Urethral Injury, Retention of urine were significantly lower (P-value $\leq 0.05$ ). Statistical analysis was done by implying one-way anova and p-value was significant. Numbers of patients were fifty in each group.

\section{DISCUSSION:}

Pakistan is among those developing countries in which prevalence of vesicle calculus is higher ${ }^{[6]}$. Various studies showed that family history and restriction of dietary calcium increases the risk of stone formation ${ }^{[8]}$.It was noted that stone formation in pediatric male patients is due to nutritional deficiencies of vitamin $A$, magnesium, phosphate and vitamin $B$ along with low protein, high carbohydrate diet intake and dehydration. Metabolic factors and some genitourinary anomalies also promote urinary stasis hence increase risk of calculus formation ${ }^{[9,10]}$. He operated a three years old child with a stone size of hen's egg. Later on, John did this procedure in 1719 and opened the bladder extraperitoneally when distended with water. He reported that 3 out of 4 patients operated by this method recovered successfully. Throughout these years of difficulties, surgeons dreamed of some means of breaking up the stone within the bladder so that fragments of stone could pass per urethra. First successful lithotrity was done by, Jean Civiale, in 1824 with the help of curved metal sound with roughened edge ${ }^{[1]}$.Until 20th century, incidence of bladder stone was high among childhood and adolescence of poor class $^{[7]}$.

Urinary calculi in children are categorized into three epidemiologic patterns: calculi seen in premature infants of very low birth weight, upper urinary tract calculi seen in children and adolescents and endemic bladder calculi. In developing countries endemic bladder calculi are still the most common disease in childhood $^{[11]}$.Open vesicolithotomy has been considered as the gold standard treatment for the patients of bladder calculi with high success rates. With the advancement in new techniques and practical experiences of endourologists, endoscopic approach with minimally invasive and non-invasive procedures are becoming more common in dealing pediatric male patients with vesicle calculus ${ }^{[12]}$.

Different studies showed that vesical calculi were more common i $\mathrm{m}$ male patients $^{[6,11,13,14,15,16,17]}$. In our study we have compared ureteroscopic cystolithoclasty with open vesicolithotomy in hundred male pediatric 
patients with mean age of 8 years (1-15 years) and almost similar studies were conducted by other researchers ${ }^{[6,13,14,15]}$. Average hospital stay of 1-3 days in Group-A and 5-7 days in Group B and 2.6 days of endourological procedure and 4.8 days of open surgery were documented by other researchers in their studies ${ }^{[13,14]}$.

It has also observed that the long hospital stay of 2.9 days in cystolitholapaxy and 7.9 days of open vesicolithotomy in adult patients ${ }^{[6]}$. Compared to their studies hospital stay is short in our study, it was 2-3 days (average 2.5days) in Group-A and 3-5 days (average 4 days) in Group-B. Current study involved the groups having same stone size $i-$ less than $20 \mathrm{~mm}$. while Al-Marhoon MS and colleagues ${ }^{[13]}$ has mentioned the stone size of $0.7-5 \mathrm{~cm}$ (mean 2.8). Duration of catheter stay was less in our study, 1-3 days (average 2 days) in Group-A and 3-5 days (average 4 days) in Group-B, as compared to 2-3 days of cystolitholapaxy and 57 days of open cystolithotomy of Rafique Ahmed and coworkers ${ }^{[14]}$ in pediatric patients. While 2.2 days of cystolitholapaxy and 7.33 days of open cystolithotomy reported by a study ${ }^{[6]}$ and 3.5 days of percutaneous suprapubic cystolitholapaxy and 8.5 days of open cystolithotomy mentioned is also mentioned by a similar study ${ }^{[15]}$ in male patients. Stone free rate in our study was $96 \%$ in Group A and $100 \%$ in Group-B which is comparable with the study where the MPCCL was used for vesical stone treatment. There Stone free rate is $91.6 \%$ and increased to $100 \%$ after second session of $\mathrm{MPCCL}$ and there complications of hematuria and urinary retention are also comparable with our endoscopic complications and also with $97 \%$ of intracorporeal lithotripsy and $100 \%$ of open cystolithotomy ${ }^{[14]} 100 \%$ clearance in both Groups, ${ }^{[15]} 100 \%$ in both Groups and $100 \%$ in open cystolitotomy ${ }^{[16]}$.

In our study complication rate after ureteroscopic cystolithoclasty was $5(10 \%)$ with complications of urethral injury $(2 \%)$, retention of urine $(4 \%)$ and urinary tract infection (4\%). Urethral injury of $5 \%$ was reported by sami ullah ${ }^{[9]}$ in their studies and retention of urine $(1 \%)$ is mentioned by Ali Sher Khosa and colleagues ${ }^{[18]}$, which is comparable with our study. Another Study conducted using penumatic lithoclast in pedriatic patients with complications of Hematuria 5\%, Urinary tract infection $2.5 \%$ and urinary retention $0.8 \%{ }^{[19,20]}$, which has to some extent resemblance with our study. Fragoso et al mentioned in their study the benefits of minimal access cystolithotomy over 'open' vesical surgery especially in view if recurrent stone formation in children ${ }^{[21]}$.

Complication rate of open vesicolithotomy was $9(18 \%)$ with complication of retention of urine $(2 \%)$, urinary tract infection $(8 \%)$, wound infection (2\%), hematuria (2\%) and fever $(4 \%)$. Rafique Ahmad ${ }^{[15]}$ has noted wound infections of $3(6 \%)$ and hematuria of $0(0 \%)$ in children. Wound infection $5(25 \%)$, hematuria $1(5 \%)$ and fever $11(55 \%)$ was also mentioned by Ahmed Turki Obaid ${ }^{[17]}$, Sami ullah ${ }^{[9]}$ has observed $1(5 \%)$ fever in adult patients of open vesicolithotomy. Another study reported that retention of urine $18(15.9 \%)$ in patients of endemic bladder stone treated with open vesicolithotomy ${ }^{[16]}$. So the complications observed in our study were less as compared to above mentioned studies.

Advancement in surgical field, miniaturization of endourogical instruments and availability of practical experience of endourology has significantly changed the treatment strategy of pediatric bladder calculus. Currently bladder calculi in pediatric male Group are managed by different modalities including extracorporeal shockwave lithotripsy, transurethral cystolithotripsy, open cystolithotomy and percutaneous suprapubic cystolithotripsy depending upon the availability of skills and gadgets ${ }^{[6,18]}$. ESWL is considered as first line of treatment in managing pediatric bladder calculi $[6,7]$. But in children its application may be questionable because it require sedation, as bladder is a capacious pouch so the stone fixation is very difficult and in case of large or hard stones multiple sessions are needed to achieve higher success rate which increases the chances of complications that is why ESWL could not get popularity for the treatment of pediatric bladder calculus in Pakistan.

\section{CONCLUSION:}

Ureteroscopic cystolithoclasty is an innovative method for managing pediatric male patients of bladder calculus as compared to conventional open vesicolithotomy, though there are still a few complications with the help of endoscopy 
even then on the basis of minimal invasion, less hospital stay, cost effective treatment, cosmetically acceptable, safe and dynamic procedure for the pediatric male patients of bladder calculus.

CONFLICT OF INTEREST: All authors disclose no conflict of interest.

\section{G R A N T S UPPORT \& FINANCIAL DISCLOSURES: None.}

\section{REFERENCES:}

1. Soliman NA, Rizvi SA. Endemic bladder calculi in children. Pediatric Nephrology. 2017 Sep 1;32(9):1489-99.

2. Masood A, Khan IZ, Farouk K, Nisar H, Ijaz $R$, Ishtiaq $S$, Taimur M. Endoscopic management of bladder calculi in paediatric male patients: An experience with 57 patients. Isra Med J. 2019;11(3):167-70.

3. Khosa AS, Hussain M, Hussain M. Safety and efficacy of transurethral pneumatic lithotripsy for bladder calculi in children. ] Pak Med Assoc. 2012 Dec 1;62(12):1297300.

4. Donaldson J, Ruhayel Y, MacLennan S, Yuan C, Shepherd R, Thomas K, Skolarikos A, Seitz C, Petrik A, Türk C, Neisius A. Treatment of bladder stones in children: $A$ systematic review on behalf of the EAU Urolithiasis Guideline Panel. European Urology Supplements. 2019 Mar $1 ; 18(1): \mathrm{e} 580-1$.

5. Kareem DA, Abd EM. Intracorporeal Pneumatic Lithotripsy for Treatment of Vesical Stone in Children. Iraqi Academic Scientific Journal. 2017;16(1):30-4.

6. Curhan GC, Willett WC, Rimm EB, Stampfer MJ. Family history and risk of kidney stones. Journal of the American Society of Nephrology. 1997 Oct 1;8(10):1568-73.

7. Ahmadnia $\mathrm{H}$, Rostami MY, Yarmohammadi AA, Parizadeh SM, Esmaeili M, Movarekh M. Percutaneous treatment of bladder calculi in children: 5 years experience. Urology journal. 2009 Mar 12;3(1):20-2.

8. Javanmard B, Karkan MF, Razzaghi MR, Ghiasy S, Ranjbar A, Rahavian A. Surgical management of vesical stones in children: a comparison between open cystolithotomy, percutaneous cystolithotomy and transurethral cystolithotripsy with holmium-YAG Laser. Journal of lasers in medical sciences. 2018;9(3):183.

9. Ullah S, Chaudhary IA, Masood R. Comparison of open vesicolithotomy and cystolitholapaxy. Pakistan Journal of Medical Sciences. 2007 Jan 1;23(1):47.

10. Naseri M, VARASTEH A, Alamdaran SA. Metabolic factors associated with urinary calculi in children.

11. Sultan S, Aba SU, Ahmed B, Naqvi SA, Rizvi SA. Update on Surgical Management of Pediatric Urolithiasis. Frontiers in pediatrics. $2019 ; 7$. doi:10.3389/fped. 2019.00252

12. Bhuyian MA, Huq MA, Kabir M, Chowdhury SH. Endoscopic Removal of Vesical Calculus Through Suprapubic Route: A Case Report. Journal of Paediatric Surgeons of Bangladesh. 2010;1(1):74-6.

13. Jan $P$ Vandenbroucke, "Treatment of bladder stone and probabilistic reasoning in medicine" International Journal of Epidemiology, Vol.30, Issue.6, Dec 2001, Pages. 1253-1258

14. Al-Marhoon MS, Sarhan OM, Awad BA, Helmy T, Ghali A, Dawaba MS. Comparison of endourological and open cystolithotomy in the management of bladder stones in children. The Journal of urology. 2009 Jun $1 ; 181(6): 2684-8$.

15. Sahito RA, Awan MS, Baloch TA. A Comparative Study of Percutaneous Suprapubic Cystolitholapaxy Versus Open Cystolithotomy in Children. Journal of Surgery Pakistan (International). 2011 Oct;16(4).

16. Fabio Cesar Miranda Torricelli, Eduardo Mazzucchi,, "Surgicaltreatment of bladder lithiasis "Magazine of Brazilian College of Surgeons, Rev.Col.Bras.Civ.Vol.40, No.3, Rio de Janeiro May/June 2013

17. Obaid AT. A comparative study of percutaneous suprapubic cystolitholapaxy versus open cystolithotomy in adults. Medical Journal of Babylon. 2013; 10(1):11-24. doi:1812-156X-10-1

18. Ali L, Ali S, Shafieullah ON. Role of 
pneumatic lithotripsy in paediatric bladder stone: I will not cut upon stone. Khyber Medical University Journal. 2014 Apr $20 ; 6(2): 1-6$.

19. Lal B, Paryani JP. Childhood bladder stonesan endemic disease of developing countries. Journal of Ayub Medical College Abbottabad. 2015 Mar 1;27(1):17-21.

20. Girişgen İ, Yüksel S, Karcılı K, Becerir T. Evaluation of the composition of urinary tract stones in children from the Inner Western Anatolian Region in Turkey. Turk J Urol 2019; DOI: 10.5152/tud.2019.19170.

21. Forgoso AC, Steyaert H, Arnaud P, Esposito C, Estevao-Costa J, Valla JS. Minimal access surgery in the management of pediatric urolithiasis. Transl Pediatr. 2016;5(4):262-265.

\section{Authors' Contribution:}

Muhammad Khalid: study Design and final approval of manuscript.

Muhammad Faizan: Data collection, statistical analysis and literature search.

Muhammad Asif Gurmani: Over all Supervision of data collection, analysis and manuscript writing.

Amjad Ali Siddiqui: Help in data collection analysis and final draft of study.

Qadeer Ahmed Choudhary: Help in data collection analysis and final draft of study.

Zulfiqar Anjum: Manuscript writing and proof reading.

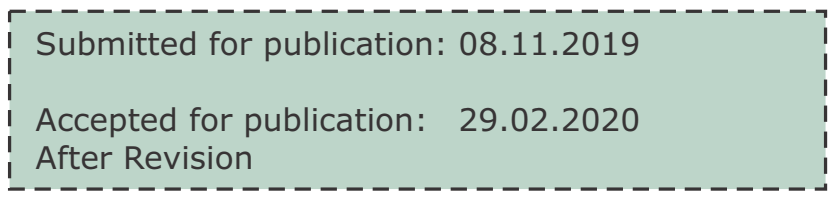

\title{
Value of a man depends upon his courage; his veracity depends upon his self-respect and his chastity depends upon his sense of honor
}

\author{
Hazrat Ali (Karmulha Wajhay)
}

